Notas Clínicas

\title{
Un nuevo caso de carcinoma de células de Merkel
}

\author{
F. Marcos Sánchez*, M. I. Albo Castaño*, E. Sánchez Díaz**, A. Viana Alonso*, \\ A. I. Franco Moreno*, F. Juárez Ucelay*
}

\section{Resumen}

Presentamos el caso de una paciente de 80 años a la que le fue extirpada una voluminosa tumoración localizada en la región axilar derecha. El diagnóstico histológico fue de carcinoma neuroendocrino primario de piel (carcinoma de células de Merkel).

El estudio de extensión realizado encontró un adenoma velloso de sigma con displasia severa.

Tras la cirugía se realizó tratamiento de radioterapia.

Posteriormente comentamos algunos aspectos clínicos, diagnósticos y terapéuticos de esta infrecuente neoplasia.

Palabras clave:

Carcinoma neuroendocrino. Carcinoma de células de Merkel.

Oncología, 2004; 27 (5):31 1-314

* Servicio de Medicina Interna

** Servicio de Anatomía Patológica

Hospital № Sa del Prado

Talavera de la Reina (Toledo) 


\section{Summary}

A case of an 80 years old woman subjected to removal of a huge tumor located in the right axillar region is presented. A histological diagnosis of primary skin neuroendocrine carcinoma (Merkel's cell carcinoma) was made.

The extension study showed a sigma villous adenoma with severe displasia.

After surgery, radiation therapy was done.

Some clinical, diagnostic, and therapeutic aspects on this rare neoplasia are made.

Key words: Neuroendocrine carcinoma. Merkel's cell carcinoma.

\section{Introducción}

El carcinoma de células de Merkel, también denominado carcinoma neuroendocrino cutáneo, supone menos del $1 \%$ de todos los tumores cutáneos malignos ${ }^{1}$.

Los estudios muestran una incidencia similar en ambos sexos ${ }^{2}$.

Se presenta de modo predominante en áreas expuestas al sol3, ${ }^{3,}$.

Diversas hemopatías malignas y otras enfermedades que cursan con inmunodepresión, como el lupus eritematoso diseminado, se han mostrado como factores favorecedores para la aparición de esta neoplasia ${ }^{5}$.

Atendiendo a la morfología celular, se distinguen tres tipos con diferente agresividad clínica: trabecular, bien diferenciado, carcinoma de células de Merkel sólido o de células intermedias y difuso o patrón de células pequeñas. Este subtipo es el más agresivo ${ }^{6}$.

Recientemente hemos tenido ocasión de diagnosticar un nuevo caso de carcinoma de células de Merkel, localizado en el tórax y dada su rareza nos parece interesante comunicarlo.

\section{Caso clínico}

Mujer de 80 años de edad, con antecedentes personales de linfocitosis diagnosticada hace 10 años, no habiendo precisado ningún tratamiento; hipertensión arterial en tratamiento medicamentoso.

Tres meses antes del ingreso denotó la aparición de una tumoración en la región axilar derecha que fue progresivamente aumentando de tamaño, no refería dolor ni fiebre. Se decidió realizar extirpación quirúrgica. En la intervención se apreció una masa tumoral de $10 \times 10 \times 5$ centímetros, que afectaba a la axila, pectorales e infiltraba la vena axilar, el plexo nervioso y la pared costal por debajo del músculo dorsal ancho. Se procedió a la exéresis de la misma.

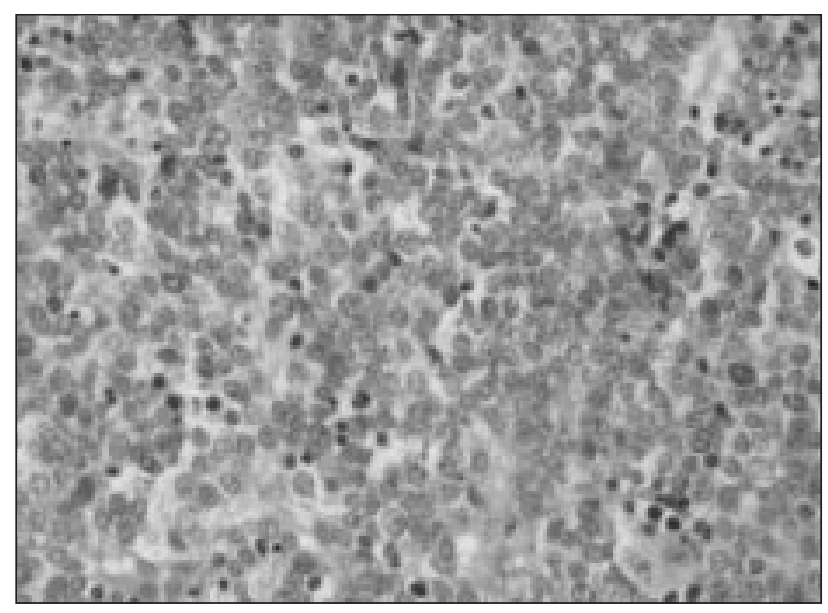

Fig. 1. Infiltración difusa por células de pequeño tamaño, escaso citoplasma y abundantes mitosis con fenómenos de apoptosis.

En el estudio de anatomía patológica se observó una infiltración difusa por células de pequeño tamaño, con escaso citoplasma, abundantes mitosis e imágenes de apoptosis (Fig. 1).

Las células tumorales eran positivas para cromogranina, NSE, sinaptofisina (Fig. 2) y mostraban positividad débil para $A E 1$ y $A E 3$, siendo negativas para $C D$ 45, Actina ML, Actina Me, S100, Vimentina, EMA, CEA, CD 57, CD 34, CD 38, CD 15, proteína básica de la mielina, tiroglobulina, CK 7, CK 20, HMB 45 y GCD FP 15. Fue informado como carcinoma neuroendocrino primario de piel (carcinoma de células de Merkel). Se recomendó descartar afectación primaria a nivel gastrointestinal y pulmón.

Otros estudios realizados: hemograma, perfil bioquímico, normales excepto LDH de $1088 \mathrm{U} / \mathrm{l}, \mathrm{CEA}$ de 7,65 U/l, Ca 125 y Ca 15.3, normales.

Radiografía de tórax, gastroscopia y ecografía abdominal normales. En la colonoscopia se observaron divertículos en el sigma y un pólipo de unos 2 centíme- 


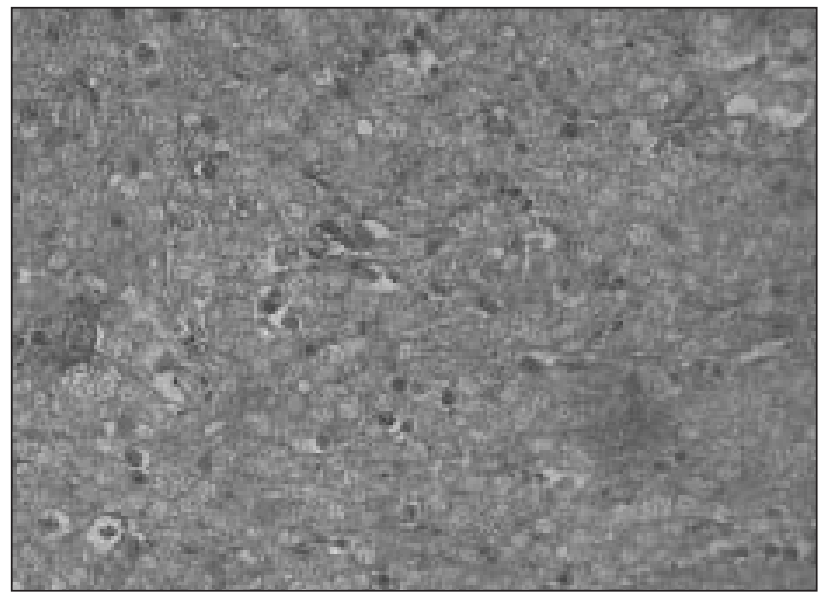

Fig. 2. Se observa la positividad de las células tumorales a la sinaptofisina.

tros de diámetro a 30 centímetros del ano, que fue biopsiado, siendo el resultado de la histología de fragmento de adenoma velloso con foco de displasia severa. Se envió posteriormente a realizar polipectomía.

TAC toraco-abdominal: normal.

Posteriormente se completó el tratamiento, efectuándose radioterapia loco-regional.

\section{Discusión}

Las lesiones primarias suelen localizarse con mayor frecuencia en la cabeza y cuello (50\%), seguido en el $40 \%$ de los casos en las extremidades y en menos del $10 \%$ de los casos en el tronco 2,7 .

Muestra una gran facilidad para presentar recurrencias locales tras la extirpación quirúrgica; así se han descrito tasas que oscilan entre el 26 y el $44 \%$. Generalmente se producen en los primeros cuatro meses tras la cirugía ${ }^{2,3,7}$

La afectación de los ganglios linfáticos regionales aparece en cerca del $60 \%$ de los casos y suele ocurrir en los primeros 8 meses $^{2,3,7}$. La tercera parte de los enfermos desarrollarán metástasis a distancia en el curso de la enfermedad, siendo las localizaciones más frecuentes el hígado, hueso, pulmón, cerebro y piel. La mitad de los pacientes las presentarán en los primeros 24 meses y la mortalidad será muy elevada.

La aparición de segundas neoplasias no es en absoluto insignificante; la mayoría de los tumores fueron carcinomas epidermoides cutáneos, seguido de hemopatías malignas y carcinomas de ovario y mama ${ }^{4}$.

Se han descrito varios casos de regresión tumoral espontánea ${ }^{8}$.

El patrón ultraestructural e inmunohistoquímico per- mite el diagnóstico diferencial con otros tumores primarios o metastásicos ${ }^{6}$. El carcinoma de células de Merkel demuestra positividad con anticuerpos para citoqueratinas de bajo peso molecular, enolasa neuronal específica y negatividad para antígeno leucocitario común (ALC), vimentina, actina, proteína S-100 y citoqueratinas de alto peso molecular ${ }^{6,7}$. El linfoma linfoblástico presenta un antígeno leucocitario común (ALC) positivo.

Para su clasificación se han descrito 3 estadios, según exista enfermedad cutánea, adenopatías locorregionales o metástasis a distancia. El patrón de células pequeñas o difuso, un alto índice mitótico (superior a 10 mitosis por campo), la presencia de invasión vascular o linfática, la existencia de metástasis a distancia, estados de inmunodepresión del tipo de hemopatías malignas o lupus eritematoso diseminado implican claramente un peor pronóstico ${ }^{3,5}$.

La localización en el tronco, como en el caso que hemos presentado, se asocia a una mayor tasa de mortalidad?.

Con respecto al tratamiento, la exéresis de la lesión primaria con unos márgenes de al menos 2 centímetros en profundidad y de 3 centímetros en sentido lateral, es el pilar fundamental del tratamiento local ${ }^{10,11}$.

La radioterapia después de la cirugía debe recomendarse en los tumores de mal pronóstico, mayores de 1,5 centímetros de diámetro, próximos a los márgenes de resección o con márgenes afectos, con evidencia de invasión vascular o linfática, con más de 10 mitosis por campo, tipo histológico de células pequeñas, tumores localmente irresecables ${ }^{10}$.

Cuando existe enfermedad diseminada, se han utilizado pautas de quimioterapia que incluyen combinaciones de doxorrubicina y ciclofosfamida, con unas respuestas completas del $38 \%$ y parciales del $30 \%, 11$. Las combinaciones de cisplatino con doxorrubicina y las que incluyen 5 fluorouracilo también se han mostrado eficaces ${ }^{12}$.

La media de duración de la respuesta es de unos 8 meses, siendo la supervivencia media desde el inicio de la quimioterapia de unos nueve meses ${ }^{12}$.

Correspondencia:

Dr. F. Marcos Sánchez

Escosura, 4 - 6은

E-28015 Madrid 


\section{Bibliografía}

1. Chuan TY, Su WP, Muller SA. Incidence of cutaneus T cell lymphoma and other rare skin cancers in a defined population. J Am Acad Dermatol 1990; 23:254-6.

2. Medina H, Urist MM, Piveash J, Heslin MJ, Bland $\mathrm{KI}, \mathrm{Be}$ enken SW. Multimodality treatment of Merkel Cell Carcinoma: Case series and literature review of 1024 cases. Am Surg Oncol 201; 8:204-8.

3. Gollard R, Weber R, Kosty MP, Greenway HT, Massullo V, Humberson C. Merkel Cell Carcinoma. Review of 22 cases with surgical pathologic and therapeutic considerations. Cancer 200; 88:1842-50.

4. Brenner B, Sulkes A, Rakowsky E, Feinmesser M, Yukelson A, Bar-haim E et al. Second neoplass in patients with Merkel Cell carcinoma. Cancer 201; 91:1358-62.

5. Lentz SR, Krewson S, Zutter M. Recurrent neuroendocrine( Merkel cell) carcinoma of the skin presenting as marrow failure in a man with systemic lupus erythematosus. Med Ped Oncology 1993; 21:137-41.

6. Pilotti S, Rilke F, Bartoli C, Grisotti A. Clinico-pathologic correlations of cutaneous neuroendocrine Merkel Cell Carcinoma. J Clin Oncol 1988; 6:1863-73.

7. Tai PTH, Yu E, Winquist E, Hammond A, Stitt L, Tonina J et al. Chemotherapy in neuroendocrine Merkel Cell carcinoma of the skin: case series and review of 204 cases. J Clin Oncol 2000; 18:2493-9.

8. Connelly TJ, Kowalcyk AP. Another case of spontaneous regression of Merkel cell( neuroendocrine) carcinoma. Dermatol Surg 1997; 23:588-90.

9. Ott MJ, Tabane KK, Gadd MA, Stark P, Smith BL, Finkelstein DM et al. Multimodality management of Merkel Cell Carcinoma. Cancer 1999; 85:2589-95.

10. Savage P, Constela D, Fisher C, Thomas JM, Gore ME. The natural history and management of Merkel Cell Carcinoma of skin: A review of 22 patients treated at the Royal Marsden Hospital. Clin Oncol 1997; 9:164-7.

11. Krasagakis K, Almond-Roesler B, Zouboulis CZ, Tebbe B, Wartenberg E, Wolff KD. Merkel cell carcinoma: Report of ten cases with emphasis of clinical course, treatment and in vitro drug sensitivity. J Am Acad Dermatol 1990; 23:254-6.

12. Voog E, Biron P, Martin JP, Blay JY. Chemotherapy for patients with locality advanced or metastatic Merkel Cell Carcinoma. Cancer 1999; 85:2589-95. 